\title{
sciendo
}

CIVIL AND ENVIRONMENTAL ENGINEERING REPORTS

E-ISSN 2450-8594

CEER 2021; 31 (3): 0134-0151

DOI: 10.2478/ceer-2021-0038

Original Research Article

\section{CONTRIBUTION TO THE VALORIZATION OF GRANULATED BLAST FURNACE SLAG IN SOIL STABILIZATION}

\author{
Sarah DJOUIMAA ${ }^{1}$, Sabrina MISSAOUI ${ }^{2}$, Naoual HANDEL ${ }^{3}$, Madani SID ${ }^{4}$ \\ 1,3,4 University of Mohamed Cherif Messaadia, Infrares Laboratory, Souk Ahras, Algeria \\ ${ }^{2}$ University of 20August, 1955 of Skikda, Soil and hydraulic laboratory of annaba,
} Algeria

\begin{abstract}
The treatment of expansive soil is generally the most effective process for the stabilization of swelling clay. In this work, we will investigate the influence of the treatment of an expansive soil using granulated blast furnace slag (GGBS) alone and granulated blast furnace slag activated by cement (GGBS/C) by mechanical, physical and chemical tests. The results obtained show an increased $\mathrm{pH}$, an improved plasticity as well as a significant reduction in swelling potential and swelling pressure following a percentage increase in additives. In addition, a change in the adsorption of methylene blue molecules (VBs) and in the microstructure of the expansive soil is observed after treatment. Utilization of both GGBS alone and GGBS activated by cement has a significant effect on the behavior of the swelling clay but the GGBS activated by cement exhibits superior results. The use of GGBS in the stabilization of soil will have both economic and environmental benefits.
\end{abstract}

Keywords: swelling pressure, granulated blast furnace slag, cement, stabilization, SEM analysis

\footnotetext{
${ }^{1}$ Corresponding : civil engineering department, university of Mohamed Cherif Messaadia, infrares laboratory, Souk Ahras, 41000, Algeria, e-mail: gc.djouimaa@yahoo.fr
} 


\section{INTRODUCTION}

Soil swelling is a disruptive phenomenon that may translate into damage to surface-built, structures or buried works [1,2]. Geotechnical engineers observed in the arid region of Souk Ahras (Algeria) degradation of structures, provoked by soil swelling. The latter is a phenomenon provoked by a change in the volume of expansive soils resulting from variations in soil water content in arid and semiarid areas [3]. Researchers have used several soil treatment methods [4,5]. Including additives such as lime, cement, fly ash or other hydraulic binders, and found that the geotechnical characteristics of the swelling soil were significantly improved. Stabilization of soils is generally achieved by improving their geotechnical properties through the reuse of swelling soils or soils with poor geotechnical characteristics to ensure the safety and stability of structures built on such soils $[6,7,8,9]$.Several authors have shown that the treatment involves a cation exchange process whereby calcium ions contained in an additive such as cement or other materials are replaced by sodium ions present in the clay. The incorporation of additives fills the pores of the soil matrix, and small particles bind together $[10,1]$. These reactions lead to increased rigidity of the soil structure, which in the short term by flocculation and agglomeration of particles and the formation of a large number of rigid bonds. These bonds in the clay particles form new cementitious compounds such as calcium silicate hydrates $(\mathrm{CSH})$, and calcium aluminates hydrates $(\mathrm{CAH})$ which leads to increased soil density and causes a change in its cation exchange capacity (CEC). Chemical stabilization results in high $\mathrm{pH}$ values causing dissolution of silica and alumina in the clay particles. The dissolved particles react with the calcium provided by the hydraulic binder generating over the long-term pozzolanic reactions [11, 12, 13]. The latter cause reduction in water sensitivity, playing thereby an important role in the stabilization of soils. GGBS is a by-product of blast furnace iron production. This slag is widely used as a primary constituent in the manufacture of hydraulic road binders. The latterare obtained by rapid cooling in water, yielding a glassy structure, which confers to them hydraulic properties [14, 15]. Utilization of slag products in Algeria is limited to some rare applications despite the substantial annual production (500.000 tons). For instance, cement plants use a small percentage of that production as a secondary additive $(<20 \%)$ and the rest is stored in the open air with all the potential environmental issues that may arise. Therefore, the use of this industrial waste as a hydraulic binder in improving the geotechnical properties of fine soils constitutes a promising solution since it helps to reduce both the considerable industrial waste and the cost of soil stabilization materials [16]. Numerous studies have confirmed that slag can induce pozzolanic reactions if activated by alkali, i.e. used in combination with another binder such as cement or lime. 
[17] demonstrated that the addition of GGBS improved both the maximum dry density (MDD) and the unconfined compressive strength of the soil. Also, the results obtained from triaxial tests show a decrease in the cohesion of the soil with increase in the internal friction angle, which makes the soil more frictional and resistant. The California Bearing Ratio (CBR) was found to increase with increasing GGBS proportion, which increases the density of the soil and improves thereby the load-bearing capacity and stability of the constructed geotechnical structure.

[18] investigated a soil layer stabilized by lime-activated GGBS and reported a significant improvement in CBR, unconfined compressive strength and in the compactness of the soil, improving as a result the mechanical resistance of the mixture. This effect can be explained by the pozzolanic reactions of the silica present in the GGBS/ lime as well as by the formation of C-S-H compounds exhibiting cementing properties in the presence of reactive siliceous and aluminous materials and water.

[19] employed GGBS with fly ash and lime. The test results showed that these additives effectively improved both the texture and plasticity of the treated soils and can consequently be utilized for soil stabilization.

In the present research, we investigate the stabilization of an expansive soil extracted from the region of Souk Ahras with granulated blast furnace slag alone $(100 \%$ GGBS $)$ and with cement-activated granulated blast furnace slag $(85 \%$ GGBS $+15 \%$ Cement)at different proportions $(4 \%, 8 \%, 12 \%, 16 \%$ and $20 \%)$. Properties such as plasticity, swelling pressure and swelling potential are studied. In addition, the influence of these additions on the clay microstructure is investigated by means of a scanning electron microscope (SEM).

\section{MATERIALS AND METHODS}

\section{Soil}

The soil object of this study is located at Ain Dalia in the western side of Souk Ahras city (Algeria), from a depth of 4 to $6 \mathrm{~m}$, it is covered by the formation of clayey marl, with sandstone and conglomerates, and it has a brown or black colour. The physical and chemical properties are shown in Tables 1 and 2. The Xray diffraction analysis performed on the natural soil is given in figure (1) it showed that the main components in the soil are: Montmorillonite, Illitemontmorillonite, Quartz, Kaolinite, and Calcium Carbonate, and Anatase, syn. 


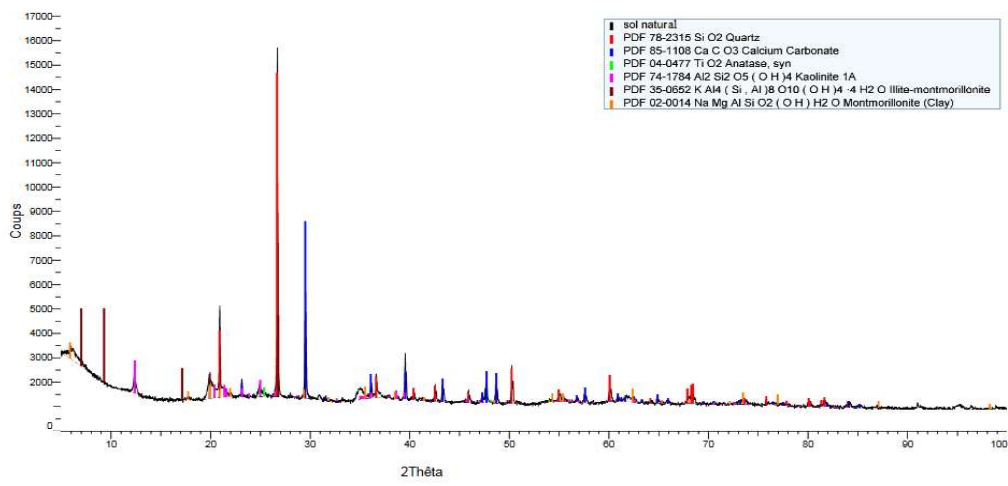

Fig. 1. X ray diffraction for the natural soil

\section{Cement}

The cement used is Portland cement CEM II / CPJ 42.5, manufactured by the hadjr essoud cement company in Annaba (Algeria); the chemical characteristics are given in table 3 .

\section{Granulated Blast Furnace Slag (GGBS)}

It was collected from El-Hadjar factory (Annaba), which is obtained by a rapid cooling of the slag using water. This leads to the formation of gray sand; the chemical characteristics are summarized in table 4.

\subsection{Sample preparation}

The soil studied was dried in an oven for $24 \mathrm{~h}$ at $105^{\circ} \mathrm{C}$ and then finely ground. The GGBS was dried then subjected to grinding in a Micro Deval machine for $12 \mathrm{~h}$. Several combinations were used to improve the characteristics of the soil studied. Beside the $0 \%$ for the control sample, GGBS contents considered were of $4 \%, 8 \%, 12 \%, 16 \%$, and $20 \%$ (in dry mass) whereas the activated GGBS was prepared using $85 \%$ of GGBS with $15 \%$ of cement then used in proportions of $4 \%, 8 \%, 12 \%, 16 \%$, and $20 \%$ (in dry mass).

The mixture was dry-mixed and then moistened to the optimum water content $\left(\mathrm{w}_{\mathrm{opt}}\right)$ determined from the standard Proctor test of an untreated sample. All tests were conducted at room temperature. Our experimental study involved Atterberg limit test, methylene blue test (VBs), $\mathrm{pH}$ test, free swelling test as well as scanning electron microscope (SEM) observations of the treated and untreated soil. 
Table 1. Physical parameters of the natural soil

\begin{tabular}{|c|c|c|}
\hline Physical parameters & Standard & Value \\
\hline Natural water content, $\mathrm{w}_{\text {nat }}(\%)$ & NF P94-050(1995) & 19.10 \\
\hline $\begin{array}{l}\text { Natural wet unit weight, } \gamma \mathrm{h} \\
(\mathrm{kN} / \mathrm{m} 3)\end{array}$ & $\gamma \mathrm{h}=\gamma \mathrm{d}(1+\mathrm{w})$ & 20.06 \\
\hline Liquid limit, LL (\%) & \multirow[t]{3}{*}{ NF P94-051(1993) } & 64.56 \\
\hline Plastic limit, PL (\%) & & 30.52 \\
\hline Plasticity index, PI (\%) & & 34.04 \\
\hline$\leq 2 \mathrm{~mm}$ fraction $(\%)$ & \multirow[t]{2}{*}{ NF P94-056(1996) } & 97 \\
\hline$\leq 80 \mu \mathrm{m}$ fraction $(\%)$ & & 91 \\
\hline$\leq 2 \mu \mathrm{m}$ fraction $(\%)$ & NF P94-057(1992) & 54 \\
\hline Activity, Ac & $\mathrm{Ac}=(\mathrm{PI} / \mathrm{F} 2)$ & 0.63 \\
\hline $\begin{array}{l}\text { Value of methylene blue, VBs (\%) } \\
(\mathrm{g} / 100 \mathrm{~g})\end{array}$ & NF P94-068(1998) & 6.33 \\
\hline Total specific surface area $(\mathrm{m} 2 / \mathrm{g})$ & $\mathrm{SSA}=21 * \mathrm{Vbs}$ & 132.93 \\
\hline Calcium carbonate content (\%) & NF P94-48(1996) & 15.08 \\
\hline $\begin{array}{c}\text { Maximum dry density, } \gamma_{\mathrm{dmax}} \\
\left(\mathrm{kN} / \mathrm{m}^{3}\right)\end{array}$ & \multirow[t]{2}{*}{ NF P94-093(2014) } & 14,7 \\
\hline Optimum water content, $\mathrm{W}_{\text {opt }}(\%)$ & & 26,6 \\
\hline
\end{tabular}

Table 2. Chemical composition of the natural soil

\begin{tabular}{|c|c|}
\hline Minerals & Quantity (\%) \\
\hline $\mathrm{SiO}_{2}$ & 25,0 \\
\hline $\mathrm{TiO}_{2}$ & 2,3 \\
\hline $\mathrm{CaCO}_{3}$ & 12,6 \\
\hline $\mathrm{Al}_{2} \mathrm{Si}_{2} \mathrm{O}_{5}(\mathrm{OH})_{4}$ & 7,5 \\
\hline $\mathrm{KAl}_{4}\left(\mathrm{Si}, \mathrm{Al}_{8} \mathrm{O}_{10}(\mathrm{OH})_{4} \cdot 4 \mathrm{H}_{2} \mathrm{O}\right.$ & 48,9 \\
\hline $\mathrm{NaMgAlSiO}$ & $(\mathrm{OH}) \mathrm{H}_{2} \mathrm{O}$ \\
\hline
\end{tabular}

Table 3. Chemical composition of cement

\begin{tabular}{|c|c|c|c|}
\hline Minerals & Quantity (\%) & Minerals & Quantity (\%) \\
\hline $\mathrm{SiO}_{2}$ & 23,8 & $\mathrm{Na}_{2} \mathrm{O}$ & 0,6 \\
\hline $\mathrm{CaO}$ & 61,5 & $\mathrm{~K}_{2} \mathrm{O}$ & 0,57 \\
\hline $\mathrm{AL}_{2} \mathrm{O}_{3}$ & 5,2 & $\mathrm{Cl}^{-}$ & 0,1 \\
\hline $\mathrm{Fe}_{2} \mathrm{O}_{3}$ & 3,2 & $\mathrm{SO}_{3}$ & 2,5 \\
\hline $\mathrm{MgO}$ & 1,5 & $\mathrm{CaO}$ libre & 0,1 \\
\hline
\end{tabular}


STABILIZATION

Table 4. Chemical composition of granulated blast furnace slag

\begin{tabular}{|c|c|c|c|}
\hline Minerals & Quantity (\%) & Minerals & Quantity (\%) \\
\hline $\mathrm{SiO}_{2}$ & 41 & $\mathrm{~S}$ & 0,67 \\
\hline $\mathrm{CaO}$ & 40,7 & $\mathrm{MnO}$ & 4,18 \\
\hline $\mathrm{AL}_{2} \mathrm{O}_{3}$ & 5,08 & $\mathrm{P}_{2} \mathrm{O}_{5}$ & 0,01 \\
\hline $\mathrm{Fe}_{2} \mathrm{O}_{3}$ & 0,97 & $\mathrm{ZnO}$ & 0,01 \\
\hline $\mathrm{MgO}$ & 6,81 & & \\
\hline
\end{tabular}

\subsection{The Atterberg limits}

The Atterberg limits were determined according to the French standard [20]. They were carried out on the treated and untreated soils in order to assess the effect of different additives. Crushed soil was sieved through $400 \mu \mathrm{m}$ sieve then mixed in dry state with various percentages of GGBS and GGBS/cement $(4 \%$, $8 \%, 12 \%, 16 \%$, and $20 \%$ ) by mass, then, water was added to the mixture and mixed again to obtain a homogeneous soil.

\subsection{Methylene blue value}

To investigate the influence of stabilization on the methylene blue values of the soil of Ain Dalia, measurements of the amount of methylene blue adsorbed were conducted according to the French standard [26] on the soil with the different percentages of GGBS and cement-activated GGBS.

The methylene blue test is the quantity expressed of methylene blue adsorbed per $100 \mathrm{~g}$ of soil. It is carried out by successively adding quantities of blue solution to a suspension of material kept under agitation and monitoring the adsorption as it occurs. A drop of suspension is taken and placed on a filter. As soon as a blue halo appears around the spot, the absorption of methylene blue on the clay particles is considered complete. It allows the characterization of active clay minerals in the soil.

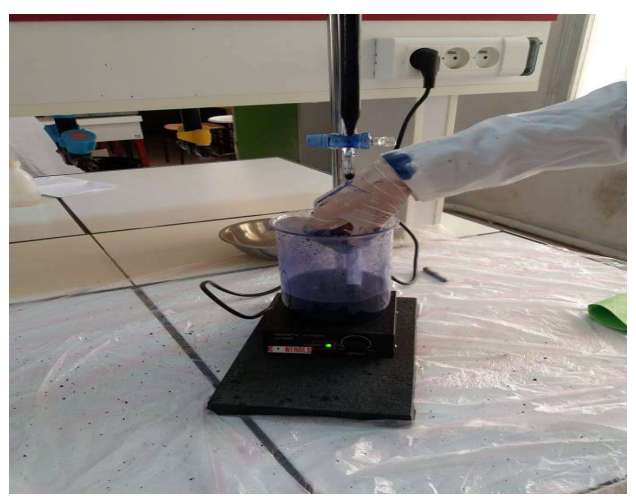

Fig. 2. Methylene blue test 


\subsection{PH measurement test}

The $\mathrm{pH}$ is a coefficient that characterizes the acidity or alkalinity of a soil, generally due to the abundance of calcium ions. Measurement of the $\mathrm{pH}$ allows determining the solubility of minerals and the movement of ions in the soil. The measurements were taken according to the standard test [27] using a $\mathrm{pH}$ meter. For this purpose, $20 \mathrm{~g}$ of dry soil were dissolved in $100 \mathrm{ml}$ of distilled water, and the resulting mixture was stirred for 2 hours to obtain a homogeneous solution. The $\mathrm{pH}$ tests were carried out on the soils studied at different percentages of GGBS and GGBS/Cement in order to assess the influence of additives on $\mathrm{pH}$.

\subsection{Free swelling test}

Free swelling tests were performed following standard [28] on the untreated soil and the treated soil compacted at the optimum water content obtained according to Standard Proctor conditions. The specimens were prepared in cylinders with a diameter of $50 \mathrm{~mm}$ and a height of $20 \mathrm{~mm}$. Next, they were filled with water and loaded with a low pressure. The sample swelled until stabilization, which allowed calculating the swelling potential. The latter is defined as the percentage ratio between the increases in specimen height $(\Delta \mathrm{H})$ under a standard stress to the initial height of specimens $\left(\mathrm{H}_{0}\right)$. The swelling pressure was determined by loading the sample until stabilization, and the load was gradually increased until the specimen returned to its initial volume.

\section{RESULT AND DISCUSSION}

\subsection{Effect of additives on the atterberg limits}

The liquid limit decreased slightly by $13.7 \%$ for an addition of $8 \%$ of GGBS and continues to decrease gradually to a percentage of $28 \%$ with a $20 \%$ of GGBS. Consistent with the findings in the literature [29]. Similar behaviour was observed with the addition of different percentages of activated GGBS; addition of $8 \%$ is accompanied by $17.54 \%$ decrease in the liquid limit and then continues to decrease to $25.12 \%$ with $20 \%$ of activated GGBS. The same behaviour was observed by $[30,17]$. This may be due to the decrease in the specific surface area resulting from the cations exchange between $\mathrm{Na}+$ present in the soil and $\mathrm{Ca} 2+$ ions of the additive (Figure.3.a).

The plastic limit starts to increase from a value of 5\% following an addition of $8 \%$ of activated GGBS until it reaches $18 \%$ with a $20 \%$ addition of activated GGBS compared to the non-treated soil. According to [31], the increase in the plastic limit of clays with an additive is considered significant in the sense that the plastic limit is the best indicator of the initial percentage of GGBS needed to achieve the desired changes. 
By contrast, the plastic limit of the soil treated with GGBS alone decreases progressively to a value of $11.43 \%$ with a $20 \%$ addition of GGBS. This has been reported by $[32,33]$. The decrease in plasticity is attributed to the different cation exchange between soil and GGBS, which decreases the thickness of the double layer (Figure.3.b).

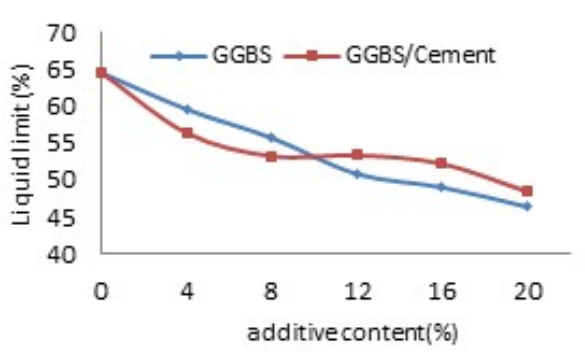

(a)

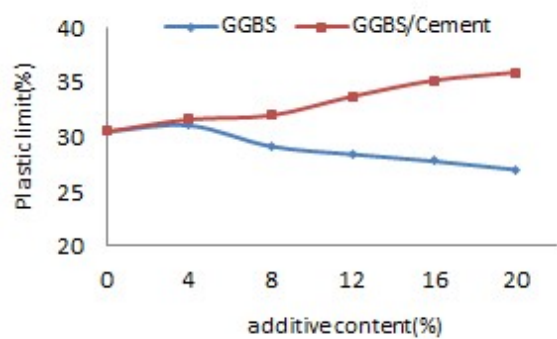

(b)

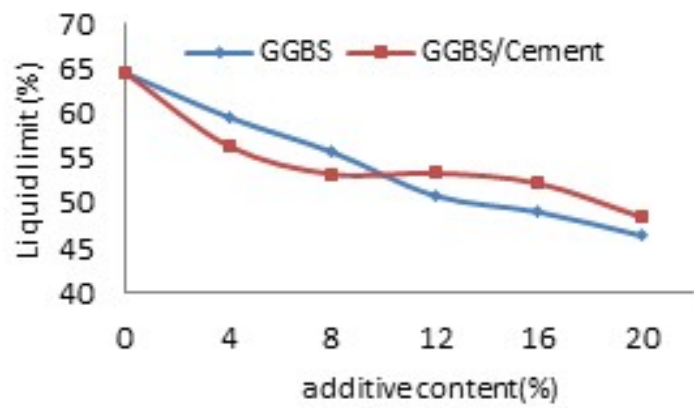

(c)

Fig. 3. Effect of the treatment on the atterberg limits: a) liquid limit, b) plastic limit, c) Plastic index

Addition of GGBS decreases the plasticity index of the treated soil by $43 \%$ (Figure .3. c), which reflects an improvement in the consistence of the soil. However, for soil treated with cement-activated GGBS, this index decreases by more than $63 \%$. This means that the soil is less plastic and as a result the bonding of adjacent particles of the soil is significantly improved [29].

\subsection{Effect of additives on the methylene blue values (VBs)}

To characterize the reactivity of the clay fraction in the soil, changes in methylene blue values [34] in soil treated with different percentages of GGBS and activated GGBS are shown in figure 4 . VBs values vary inversely with the percentage of additives [35]. Addition of $20 \%$ of GGBS reduces VBs by around $63 \%$ and $84 \%$ after treatment with $20 \%$ of cement-activated GGBS. This can be explained by 
decrease in adsorption of positively charged methylene blue molecules by the surface of negatively charged clay and this through the decrease of active clay minerals responsible for developing specific internal and external surfaces in the soil.
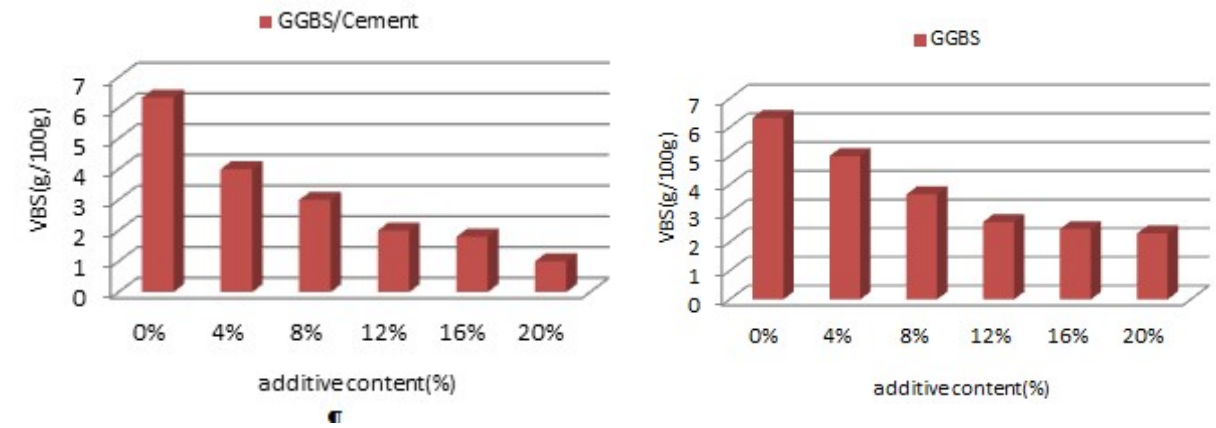

(a)

(b)

Fig. 4. Effect of the treatment on the methylene blue values: a) with GGBS/Cement, b) with GGBS

\subsection{Effect of additives on the $\mathrm{pH}$ value}

Different GGBS and cement-activated GGBS contents were blended with the soil to study their effects on $\mathrm{pH}$ value. From figure .5, one can see that the non-treated soil shows a $\mathrm{pH}$ of 7.83 . This value reaches 11.25 for $8 \%$ of GGBS alone and 12.38 for $8 \%$ of cement-activated GGBS. Beyond this value, the increase in the percentage of additive leads to a slight increase; for a percentage of $20 \%, \mathrm{pH}$ values are 11.34 and 12.53 for GGBS alone and cement-activated GGBS, respectively.

Similar observations were reported by $[36,37]$ suggested that the value of additive corresponding to a gradual increase in $\mathrm{pH}$, and which affect the shape of the curve, is the initial percentage to stabilize the fine-grained soil. This initial percentage is necessary for the occurrence of the pozzolanic reaction, which is responsible for enhancing several geotechnical parameters of the treated soil. 


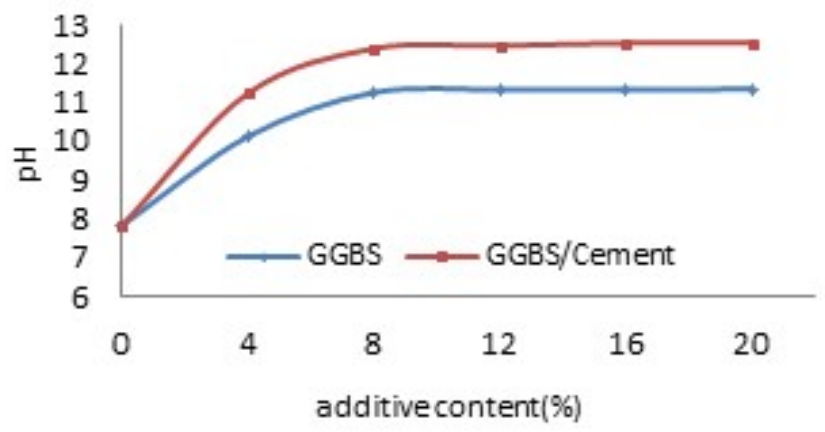

Fig. 5. Effect of the treatment on the $\mathrm{pH}$ values

\subsection{Effect of additives on the free swelling, swelling potential and swelling pressure}

As can be seen from figure 6, the untreated Ain Dalia soil present an intense swelling due to strong hydration and saturation of micropores of sodium cations $(\mathrm{Na}+)$ concentration.

A treatment with $4 \%$ of cement-activated GGBS and GGBS alone decrease the percentage of swelling by $36 \%$ and $22 \%$, respectively. A treatment with $12 \%$ of activated GGBS or GGBS alone provokes a decrease in swelling by $60 \%$ and $45 \%$ respectively. The reason for this is that the quantities of the additives are insufficient for a complete saturation by calcium.

A $20 \%$ addition of cement-activated GGBS induces a significant decrease in swelling (80\%) whereas for the same percentage of GGBS alone, the swelling decreases only by $68 \%$. This significant reduction in swelling with the increase of additives percentage is attributable to the complete saturation of the soils by the calcium provided by the additive. The soil treatment involves the replacement of sodium cations $\mathrm{Na}+$ present, which have a high hydration energy, by the calcium cations $(\mathrm{Ca} 2+)$ provided by the GGBS and the activated GGBS. This leads to decreased pores and deformation of the aggregates. 


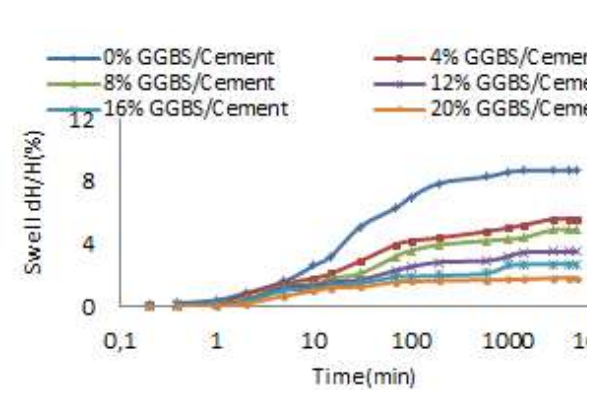

(a)

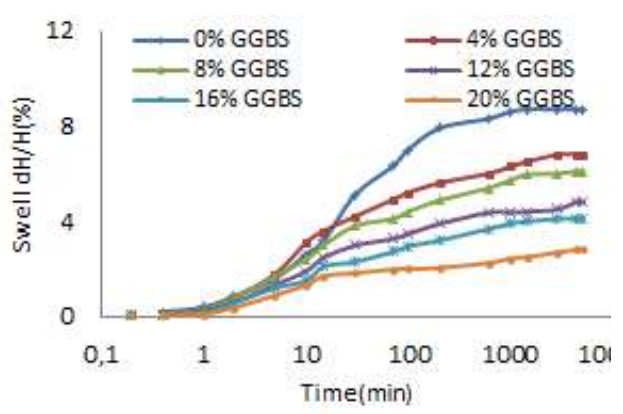

(b)

Fig. 6. Effect of the treatment on the evolution of swelling versus time: a) with GGBS/Cement, b) with GGBS

Swelling potential, which is defined as the maximum deformation value obtained from the free swelling test together with swelling pressure are shown in figures 7 and 8 . The swelling potential decreases proportionally with different percentages of activated GGBS from $36 \%$ to $80 \%$ and from $22 \%$ to $68 \%$ for the GGBS alone. Our results represent a significant decrease in the swelling of an expansive soil. Addition of $4 \%$ and $20 \%$ of activated GGBS decreases significantly the swelling pressure from $42 \%$ to $82 \%$. However, additions in the range $4-20 \%$ of GGBS alone show a reduction from $24 \%$ to $57 \%$ (Figure. 8).Thus; the greater the amount of addition, the lower is the swelling pressure. Indeed, GGBS induces a decrease in fine particles and an increase in coarse particles due to the primary pozzolanic reaction and flocculation of the fine soil particles. Addition of activated GGBS allows the creation of a more granular material and improvement of the plasticity of the treated soil because of the cationic exchange reactions and the formation of new hydrates (C-S-H and C-A-H) that take place.

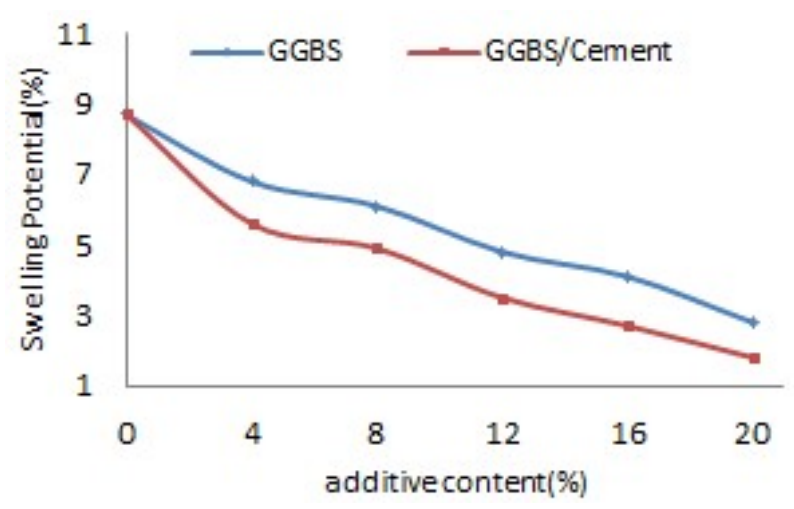

Fig. 7. Effect of the treatment on the swelling potential 


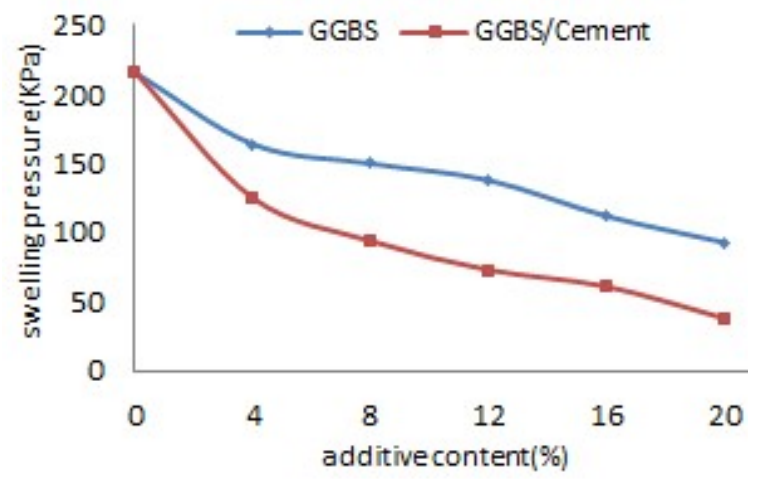

Fig. 8. Effect of the treatment on the swelling pressure

\subsection{Effect of additives on the microstructure of the soil}

To investigate the influence of the treatment on the microstructural changes of the natural soil treated with different amounts of GGBS and cement-activated GGBS, we used scanning electron microscopy (SEM).

SEM images obtained from the untreated soil show a relatively compact texture, consisting of clay aggregates in small and individualized expansive clusters separated by pores. Soil swelling leads to a decrease in aggregates and an increase in pores thickness. Addition of GGBS alone or activated GGBS to the soil produces a change in the microstructure starting from a percentage of $12 \%$ where the number of macropores in the treated soil decrease compared to the natural soil. As one can see from figure 10, there are hydration products in the pores, which mean that the soil is integrated in the active zone due to the influence of the activated GGBS. With the increase of additives percentage to $20 \%$ of GGBS alone or activated GGBS, the proportion of micropores seems to be stable with a dense internal structure, which comprises agglomerations of soil aggregates filling the macropores. In addition, it can be seen that cementitious products (C-S-H or C-A$\mathrm{S}-\mathrm{H})$ formed at the surface of the soil grains, produced by pozzolanic reactions, which are conducive to increased soil rigidity $[38,39]$ 

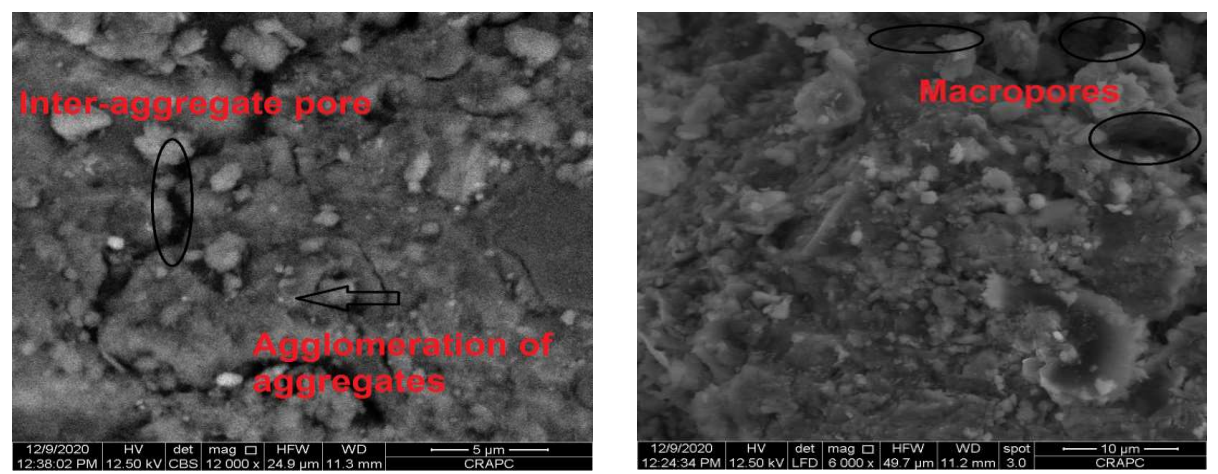

Fig. 9. SEM analysis for the natural soil
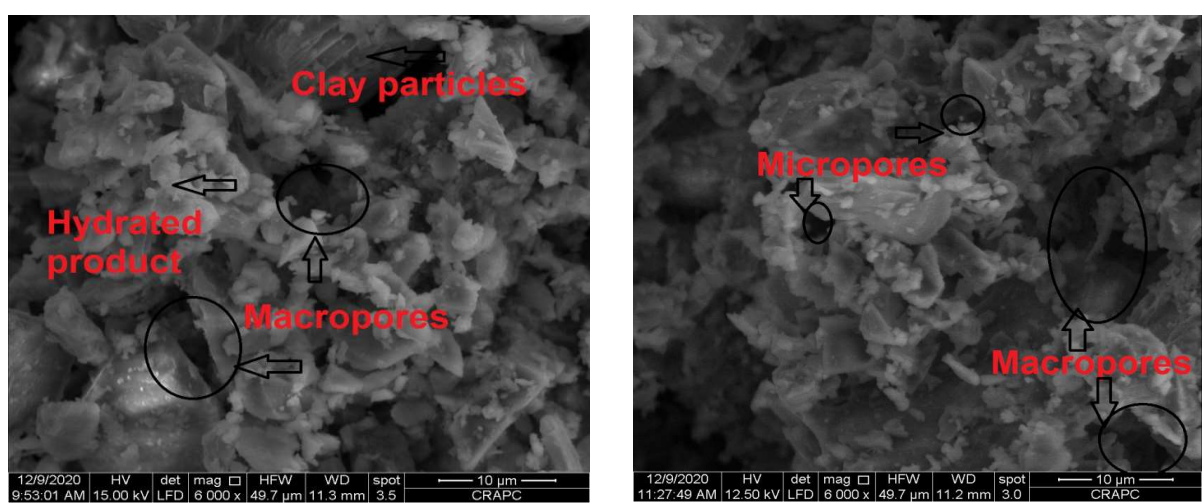

Fig. 10. SEM analysis for the soil treated with $12 \%$ GGBS
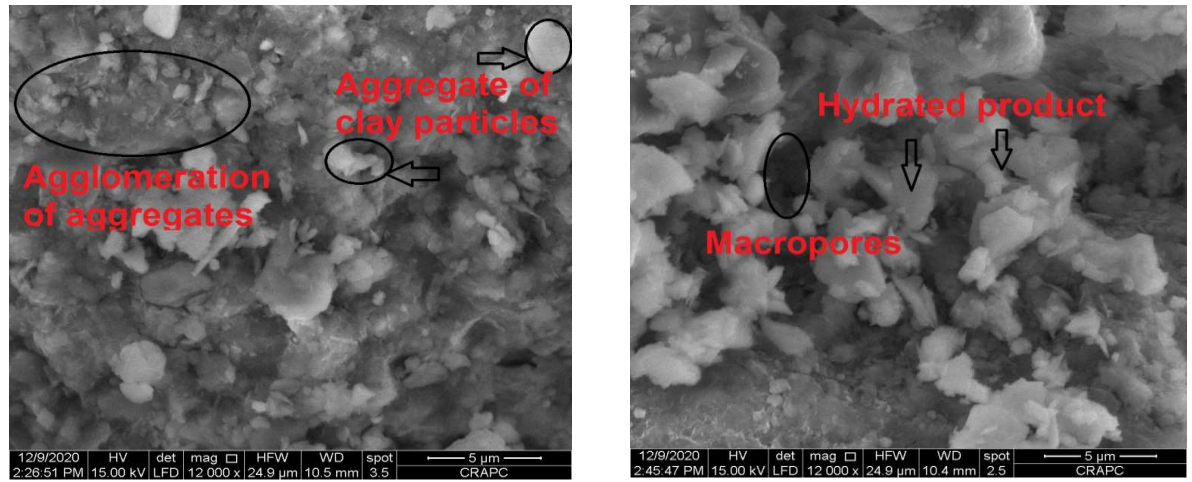

Fig. 11. SEM analysis for the soil treated with $12 \%$ GGBS/Cement 

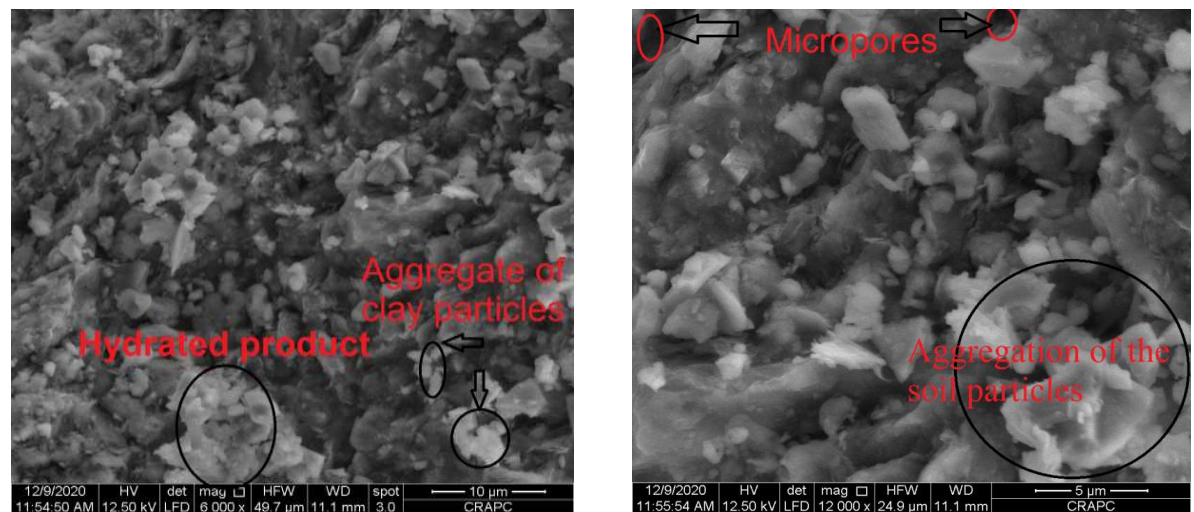

Fig. 12. SEM analysis for the soil treated with $20 \%$ GGBS
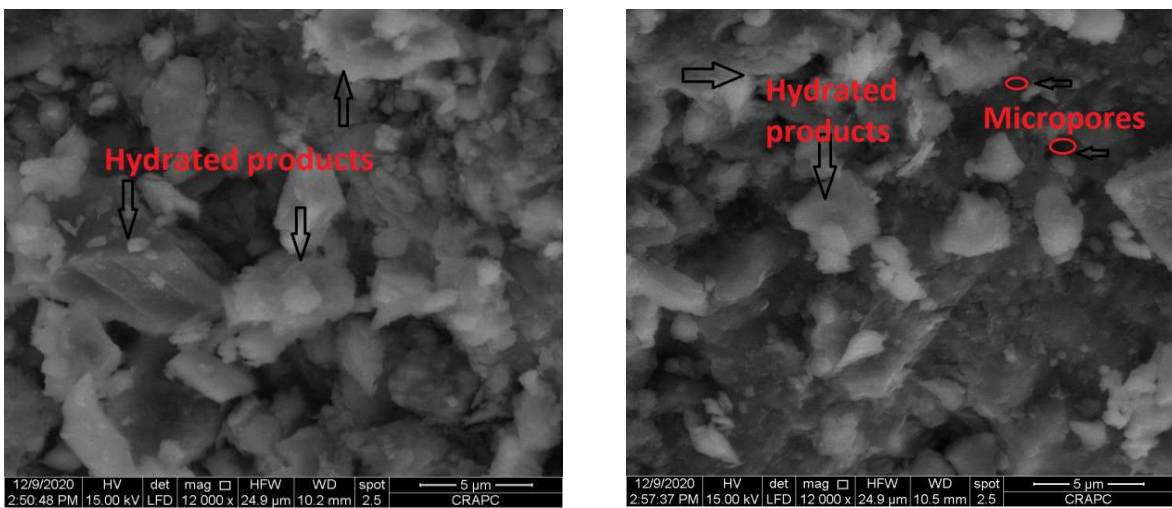

Fig. 13. SEM analysis for the soil treated with $20 \%$ GGBS/Cement

\section{CONCLUSION}

This study aims to investigate through laboratory tests the iour of expansive soil stabilized with different percentages of GGBS and cement-activated GGBS. From the results obtained, the following conclusions can be drawn:

The increase in GGBS alone causes a reduction in liquid limit and an increase in plastic limit; these changes result from the initial physico-chemical reaction, which releases heat and causes as a result evaporation of water from the soil. Increasing the activated GGBS leads to increased liquid and plastic limits. Thus, these results confirm the improved workability and better reinforcement of soil. For both types of additives, beyond a certain addition percentage, the treatment reduces the plasticity index, which makes the soil less plastic and reduces the methylene blue adsorption capacity. This stems from a reduction of the clay surface leading thereby to reduction of swelling. 
Increasing the content of GGBS or GGBS/Cement leads to high $\mathrm{pH}$ values, which allows the formation of cementitious products responsible for binding soil particles. However, soil treated with activated GGBS shows a higher $\mathrm{pH}$ than the one treated with GGBS alone.

For both additives, $8 \%$ is the initial percentage to be added, as obtained from a $\mathrm{pH}$ threshold equal to 12.4, to allow pozzolanic reactions to occur. The latter are conducive to better dissolution of silica $\left(\mathrm{SiO}_{2}\right)$ and of alumina $\left(\mathrm{Al}_{2} \mathrm{O}_{3}\right)$ contained in the soil particles and thereby to long-term improvement of the soil.

Significant reductions in the percentage of swelling were obtained following the treatment with both activated and non-activated GGBS. Samples treated with $20 \%$ of activated GGBS show the most significant effect with $80 \%$ decrease in swelling, which corresponds to a decrease in swelling pressure by $82 \%$.For samples treated with $20 \%$ of GGBS alone, the reductions are $68 \%$ and $57 \%$ for swelling and swelling pressure, respectively. This significant decrease is related to the effect of the new cementitious phases (C-S-H and C-A-H) following the pozzolanic reactions. This improvement in swelling properties is an encouraging indicator for the use of industrial wastes.

Analysis of the soil microstructure by scanning electron microscope according to the different percentages of GGBS alone and activated GGBS shows important transformations in the microstructure of the treated soil. The inter-aggregate porosity of the untreated soil is at the origin of change in porous volume. Indeed, this volume is altered by flocculation during the incorporation of activated GGBS or GGBS alone in the soil due to the effect of calcium ions brought by the additive. This leads to pozzolanic reactions, which create new hydrates by binding aggregates and filling the inter-aggregate pores. This results in the reduction of water sensitivity of clay particles and leads to a rigid structure by reducing soil swelling.

Samples stabilized with cement-activated GGBS show better results compared to those stabilized by GGBS alone.

Finally, one can say that the use of industrial waste is very effective in the reinforcement and stabilization of soil and in the protection of the environment.

\section{REFERENCES}

1. Chen, F-H 1975. Foundations on expansive soils. Elsevier, Devel Amsterdam, 279.

2. Malekzadeh, $M$ and Bilsel, $H$ 2014. Hydro-mechanical behavior of polypropylene fiber reinforced expansive soils. KSCE Journal of Civil Engineering 18(7),2028-2033. 
3. Khemissa, M and Mahamedi, A 2014. Cement and lime mixture stabilization of an expansive over-consolidated clay. Applied Clay Science, 104-110.

4. Bouassida, E, Khemakhem, D and Haffoudhi, S 2015 . Study of the shear resistance of an expansive over-consolidated clay treated with hydraulic binders (in french). Innovative Geotechnics for Africa 936(6), 978-9938.

5. Henry, K-S 1999. Geotextile reinforcement of low-bearing-capacity soils, comparison of two design methods applicable to thawing soils. US Amy Corps of Engineers, Cold Regions Research and Engineering Laboratory (CRREL), Hanover 29, 99-7.

6. Djouimaa, S, Sid, M and Hidjeb, M 2018 .Effect of lime and cement on the geotechnical properties of an expansive soil. International Review of Civil Engineering (I.RE.C.E.) 9(3), 2036 - 9913.

7. Larsson, S, Rothhämel, M and Gunnar, J 2009. A laboratory study on strength loss in kaolin surrounding lime-cement columns. Applied Clay Science 44, 116-126.

8. Malekzadeh, $\mathrm{M}$ and Bilsel, $\mathrm{H}$ 2014. Hydro-mechanical behavior of polypropylene fiber reinforced expansive soils. KSCE Journal of Civil Engineering 18(7), 2028-2033.

9. Mavroulidou, M, Zhang, X, Gunn, M-J and Cabarkapa, Z 2013. Water retention and compressibility of a lime-treated, high plasticity clay. Geotech Geol Eng 31, 1171-1185 .

10. Jawad, I-T, Taha, M-R, Majeed, Z-H and Khan, T-A 2014. Soil stabilization using lime: Advantages, disadvantages and proposing a potential alternative. Research Journal of Applied Sciences, Engineering and Technology 8(4), 510-520.

11. Alrubaye, A-J, Muzamir, H and Fattah, M-Y 2016 . Engineering properties of clayey soil stabilized with lime. ARPN Journal of Engineering and Applied Sciences 11(4),1819-6608.

12. Maaitah, O-N 2012. Soil Stabilization by Chemical Agent. Geotech Geol Eng $30,1345-1356$.

13. Zhao, H, Ge ,L, Petry, T-M and Sun,Y-Z 2014 . Effects of chemical stabilizers on an expansive clay. KSCE Journal of Civil Engineering 18(4), 1009-1017.

14. Handel, N, Hafsi, B, Touati, A and Djabbar, Y 2011. Substitution of the aggregate by solid waste of blast furnace in the preparation of concrete, J.Mater. Environ. Sci 2, 520-525.

15. Handel, N 2019. Experimental investigation of the blast furnace slag based concretes filled in the thin walled steel stubs. International Review of Civil Engineering (I.RE.C.E.) 2, 117-124. 
16. Izemmouren, O and Guettala, A 2014. Effect of blast furnace slag on engineering properties of compressed earth bricks based on sulphate bearing soil (in french). Ecomaterial Symposium, Montpellier, France.

17. Ashish, K- P, Pandey, V and Krishna Murari, J-P-S 2014 . Soil stabilisation using ground granulated blast furnace slag. Journal of Engineering Research and Applications 4(2), 2248-9622.

18. Sridevi, G and Sreerama, R 2014. Efficacy of GGBS stabilized soil cushions with and without lime in pavements. International Journal of Emerging Technologies in Computational and Applied Sciences 9(2), 2279-0055.

19. Anil, K-S and Sivapullaiah, p-v 2011. Soil stabilization with waste materials based binder. Proceedings of Indian Geotechnical Conference, 15-17 December.

20. NF P94-051 1993. Determination of Atterberg's limits. Liquid limit test using Casagrande apparatus. Plastic limit test on rolled thread.

21. NF P94-50 1995. Determination of moisture content. Oven drying method.

22. NF P94-056 1996. Granulometric analysis. Dry sieving method after washing.

23. NF P94-057 1992. Granulometric analysis. Hydrometer method.

24. NF P94-48 1996. Determination of the carbonate content .Calcimeter method.

25. NF P94-093 2014. Determination of the compaction reference values of a soil type, Standard proctor test, Modified proctor test.

26. NF P94-68 1998. Determination of the methylene blue value of soil or rock material by spot testing.

27. ASTM -4972 (1995) Standard test method for $\mathrm{pH}$ of soils. Annual book of ASTM Standards, vol 04.08. Easton, PA: American Society for Testing and Materials.

28. XP P94-091 1995. Oedometer swelling test, determination of deformations by loading several test specimens.

29. Dayalan, J 2016. Comparative study on stabilization of soil with ground granulated blast furnace slag (GGBFS) and fly ash. International Research Journal of Engineering and Technology (IRJET) 03(05), 2198-2204.

30. Ouf, M.E.S 2001. Stabilization of clay subgrade soils using ground granulated blast furnace slag. Thesis School of Civil Engineering University of Leeds, UK.

31. Hilt, G-H and Davidson, D-T 1960. Lime fixation on clayey soil . Highway Research Board Bulletin 262, 20-32.

32. Mgangira, M-B 2008. Laboratory assessment of the influence of the proportion of waste foundry sand on the geotechnical engineering properties of clayey soils. Journal of South African Institution of Civil Engineering 48(1), 2-7. 
33. Cocka, E, Yazici, V and Ozaydin, V 2004. Stabilisation of expansive clays using Granulated Blast Furnace Slag (GBFS), GNFS-Lime combination and GBFS Cement. Master's Degree Thesis. Middle East Technical University.

34. Davidson, D-T and Handy, R-L 1960. Lime and lime applications. Highway Engineering Handboo, M.C Graw Hill, New York 23-98.

35. Mellal, F and Lamri, B 2010. Study of the behavior of a road embankment treated with lime in the case of the east-west motorway (in french). International Symposium on Construction in Seismic Zones, Hassiba Benbouali University of Chlef (Algeria) $26-27$.

36. AL-Rawass, A-A, Taha, R, Nelson, J-D, AL Shab, T-B and AL Siyabi, H 2002. A comparative evaluation of various additives in the stabilization of expansive of soils. Geotech Test Journal 25(2), 199-209.

37. Eades, J-L and Grim, R-E 1966. A quick test to determine lime requirements for lime stabilization. Highway Research Board Bulletin 139, 61-72.

38. Chew, S-H, Kamruzzaman, A-H-M and Lee, F-H 2004. Physico-chemical and engineering behavior of cement treated clays. Journal of Geotechnical and Geoenvironmental Engineering 130(7), 696-706.

39. Horpibulsuk, S, Rachan, R, Chinkulkijniwat, A, Raksachon, $Y$ and Suddeepong, A 2010. Analysis of strength development in cement-stabilized silty clay from microstructural considerations. Construction and Building Material 24, 2011-2021. 